\title{
Assessment of pine cone derived activated carbon as an adsorbent in defluoridation
}

\author{
Rahul Singh Thakur ${ }^{1} \cdot$ Surjit Singh Katoch ${ }^{1} \cdot$ Ankit Modi $^{2} \mathbb{C}$
}

Received: 14 February 2020 / Accepted: 14 July 2020 / Published online: 22 July 2020

(c) Springer Nature Switzerland AG 2020

\begin{abstract}
A vast population of the world is vulnerable to fluoride contaminated drinking water intake, and there are various defluoridation techniques available to date as well. But the removal of fluoride is still a challenge, especially in remote rural areas because available techniques require proper supervision and equally, ineffective due to economic issues and electricity crisis. Among all methods of defluoridation, adsorption methods are found better to carry out at the community and household level but sometimes demanded a replacement of commercial activated carbon (CAC) due to economic issues and less availability in remote areas. Hence keeping this in mind, the present study assessed the pine cone activated carbon (PCAC) as adsorbent material in the defluoridation that is easy to prepare like any other agriculture-waste material. The activated carbon was prepared using $\mathrm{KOH}$ as an impregnating agent for activation of pine cone by pyrolysis technique at $800^{\circ} \mathrm{C}$ and has been analyzed for various parameters in the fluoride removal viz. contact time, dose variation, $\mathrm{pH}$ and initial fluoride concentration. The maximum adsorption capacity of fluoride on pine cone activated carbon was found $1.34 \mathrm{mg} / \mathrm{g}$ of initial fluoride concentration $(2-12 \mathrm{mg} / \mathrm{L})$ at $\mathrm{pH}(6.8-7.0)$ with a contact period of $45 \mathrm{~min}$. Also, a comparison has been made between Pine Cone Activated Carbon (PCAC) with Commercial Activated Carbon (CAC) based on obtained results. It has been suggested that Pine cone activated carbon is efficient as well as cheap adsorbent and can be used for the removal of fluoride from drinking water in rural areas.
\end{abstract}

Keywords Pine cone - Adsorption · Defluoridation · Activated carbon · Agriculture-waste material

\section{Introduction}

The presence of fluoride traces in water is essential to prevent dental caries but if present in a larger concentration in water it may possess a threat to human health. Sometimes, fluoride is responsible for the epidemic disease of fluorosis in human and living beings due to excess intake of fluoride in drinking water $[4,15,23,26]$. Apart from fluoride toxic effect on bone and teeth, the fluoride has a toxic effect on the functional mechanism of the kidney if intake of fluoride is $4 \mathrm{mg} / \mathrm{L}$ or $12 \mathrm{mg} /$ day $[8,31,34]$. The excess of fluoride intake may also affect the intelligent quotient (IQ) of children due to sleepiness and giddiness $[25,30,40]$ and cause the functional impairment of the nervous system in the development of the infant [37]. The fluoride toxicity is responsible for the destruction of the RBCs and in lowering the hemoglobin levels as well as has the toxic effects on gastro-intestinal mucosa due to loss of microvilli [17, 22].

WHO (world health organization) recommended the desirable and permissible limit for fluoride in drinking Electronic supplementary material The online version of this article (https://doi.org/10.1007/s42452-020-03207-x) contains
supplementary material, which is available to authorized users.

Ankit Modi, ankit.mbm.civil@gmail.com | ${ }^{1}$ Centre for Energy and Environmental Engineering, National Institute of Technology Hamirpur, Hamirpur, Himachal Pradesh, India. ${ }^{2}$ Department of Civil Engineering, Indian Institute of Technology Kanpur, Kanpur, Uttar Pradesh, India. 
water as $0.5 \mathrm{mg} / \mathrm{L}$ and $1.5 \mathrm{mg} / \mathrm{L}$, respectively. According to the Indian standard code of drinking water IS 10,500:2012, the acceptable and permissible limit for fluoride in drinking water is $1 \mathrm{mg} / \mathrm{L}$ and $1.5 \mathrm{mg} / \mathrm{L}$. Till today, even there is an abundance of defluoridation techniques present in the world but, researchers are struggling to combat the epidemic disease of fluorosis and looking for efficient and cheap fluoride removal technique $[1,3,14,33,35,38]$. In India, elevated fluoride levels account for more than 200 districts in 22 states. Rajasthan, Gujarat, Telangana and Andhra Pradesh are severely affected states from fluorosis. Other states have a moderate level of fluoride in groundwater viz. Punjab, MP, Haryana, and Maharashtra. A low level of fluoride in groundwater is reported in Tamil Nadu, West Bengal, UP and Bihar $[3,14,23,38]$. The WHO has classified fluoride as a major contaminant in drinking water.

In the Indian scenario, many defluoridation techniques are very costly or cannot be used without proper supervision in rural areas as mostly suffered from economic issues and electricity. Among all existing methods, adsorption is the best technique that can be easily carried out in rural areas using cheap and effective adsorbent.

Adsorption technique is widely used for contaminant removals like iron, fluoride, and arsenic, etc. from water or any solvent $[7,27]$. It has replaced all conventional methods of purification such as distillation, absorption, and the membrane-based technique by its significant abilities in the economy and contaminant removal $[1,33,38]$. Today, many water plants used adsorbents for contaminant removal from water because adsorbent has been proved to be effective at high flow rates and produces no sludge $([2,18,39]$. Nowadays, all the filters are using adsorbent as their filtration medium in water purifiers and treatment units that help in enhancing the filtration and contaminant uptake rate. With the increasing demand for adsorbent material in the market, varieties of charcoal and activated charcoal are produced at large scale from agricultural waste and other organic material, e.g., wood chips, rice husks, nutshell, leaves, Jamun seed, saffron leaves, and many more materials [12].

So, the main focus of this research is to develop agrobased cost-effective, simple and efficient adsorbent to use in adsorption techniques for fluoride removal from drinking water.

\section{Objective}

For the present study, the specific objectives are,

1. Study of surface morphology and behavior on activated carbon derived from pine cone using potassium hydroxide $(\mathrm{KOH})$ as an activating agent,
2. Analyses of fluoride removal with varying parameters viz., contact time, adsorbent dose, $\mathrm{pH}$, and initial concentration of fluoride, and

3. Comparative study of Pine Cone Activated Carbon (PCAC) with Commercial Activated Carbon (CAC)

\section{Material and instrumentation}

For the preparation of PCAC materials and chemicals require are- Pine Cone, Sodium fluoride (NaF), SPADNS dye, Zirconyl octahydrate, $\mathrm{KOH}$ pellet for impregnation, $\mathrm{HCl}$ solution $(0.1 \mathrm{M})$ and $\mathrm{NaOH}$ solution $(0.1 \mathrm{M})$ for $\mathrm{pH}$ adjustment. The CAC was purchased from "Akshar chemicals, Gujarat, India". As per their specifications, it had a coarse-grained particle size with a mean diameter of $2.80 \mathrm{~mm}$.

Various types of instrumentation and apparatus are used for the analysis of fluoride removal and studying the surface morphology of PCAC. All the experimental works have been performed at the Centre for Materials Science and Engineering (CMSE) and the Centre for Energy and Environmental Engineering (CEEE) labs of NIT Hamirpur. The major and minor instrumentation and apparatus used in the study are; UV-VIS spectrophotometer (Agilent Cary 60 UV-Vis), high-resolution scanning electron microscope (Quanta 450 FEG), Fourier-transform infrared spectroscopy (FT-IR PerkinElmer), pH meter (Esico 1010 Digital Electric Microprocessor pH System), muffle furnace, magnetic stirrer, weighing balance, oven, pipette, conical flask and measuring cylinder.

\section{Methodology}

\subsection{Proximate analysis of PCAC}

A proximate analysis was done to understand the utility of Pine cone for charcoal formation. This method is significant in understanding the nature of base material for charcoal preparation. It includes a percentage of moisture, percentage of volatile matter, amount of ash, and fixed carbon available in organic material viz. coal, rice husk, dried leaves, solid waste, nutshell, endocarp, etc. Initially, pine cone petals are taken in a crucible and dried for complete moisture removal at $105^{\circ} \mathrm{C}$ for about $6 \mathrm{~h}$ to analyze the percentage of moisture in biomass. Then the dried sample is heated in a closed system for complete air absence at $700-950{ }^{\circ} \mathrm{C}$ for $7 \mathrm{~min}$ to analyze the percentage of volatile matter. In the last ash content is found by burning the sample at $550^{\circ} \mathrm{C}$ till ash formation. 


\subsection{Preparation of pine cone activated carbon (PCAC)}

1. Take around 8 to 10 numbers of the dried pine cone. Then break its petals and washed with normal water first to remove any dirt. After that wash it with distilled water dried at $105^{\circ} \mathrm{C}$ for about $6 \mathrm{~h}$ in an oven.

2. As the sample dry completely, take $115-120 \mathrm{~g}$ dried sample and place it in an airtight steel container for the carbonization process at a temperature of $650^{\circ} \mathrm{C}$ and keep at this temperature for $1 \mathrm{~h}$ in a muffle furnace.

3. After $1 \mathrm{~h}$, remove the steel container from the muffle furnace using tong and thermally insulated gloves. Let the container cool down completely to its room temperature. Then open the lid and keep the charcoal in an airtight container.

4. Now break the charcoal into smaller chunks (around 3-5 $\mathrm{mm}$ ) using a grinder and prepare its slurry with adding $\mathrm{KOH}$ in 1:4 with charcoal and $200 \mathrm{~mL}$ of distilled water and keep it for $6 \mathrm{~h}$. In this study, $96 \mathrm{~g}$ of charcoal pieces are taken to prepare its slurry. Then, this slurry is dried for about $8 \mathrm{~h}$ at $105^{\circ} \mathrm{C}$. Again keep it in a muffle furnace for activation at a temperature of $800^{\circ} \mathrm{C}$ for $1 \mathrm{~h}$.

5. Wash the $\mathrm{KOH}$ treated activated carbon with $0.1 \mathrm{M} \mathrm{HCl}$ solution and with distilled water to remove the excess $\mathrm{KOH}$. Wash it several times to keep the $\mathrm{pH}$ of activated carbon around 7 . In the present study, the $\mathrm{pH}$ is maintained in the range of 7 to 8 after $25-30$ times washing.

6. Finally dried the sample at $105^{\circ} \mathrm{C}$ for $6 \mathrm{~h}$ and then grind it into fine-grained particles and sieve it.

Preparation of fluoride stock and test solution.

1. First, prepare a stock solution of fluoride using $\mathrm{NaF}$. The weighted amount of $\mathrm{NaF}(22.1 \mathrm{mg})$ is added to a beaker and filled up to $500 \mathrm{~mL}$ of distilled water. The resulting stock solution of fluoride will be of $20 \mathrm{ppm}$.

2. Then prepare a SPADNS reagent by adding $239.5 \mathrm{mg}$ in $125 \mathrm{~mL}$ distilled water and Zirconyl acid reagent by adding $25 \mathrm{mg}$ Zirconyl chloride octahydrate with $87.5 \mathrm{~mL} \mathrm{HCl}$. Make up this resulting mixture up to $125 \mathrm{~mL}$ adding distilled water (IS 3025 (Part 60) 2008).

3. To prepare $0.1 \mathrm{~N} \mathrm{NaOH}$, add $0.4 \mathrm{~g} \mathrm{NaOH}$ in $100 \mathrm{~mL}$ distilled water.

4. Take $2.045 \mathrm{~mL} \mathrm{HCl}$ in a beaker and makeup to $250 \mathrm{~mL}$ using distilled water, therefore, we get $0.1 \mathrm{~N} \mathrm{HCl}$ solution.

5. Now, the test solution of fluoride will be prepared using a stock solution by applying the dilution formula with different concentration of $2 \mathrm{ppm}, 4 \mathrm{ppm}, 6 \mathrm{ppm}$, 10 ppm, 12 ppm, and so on.
6. $\mathrm{pH}$ adjustment is done using $0.1 \mathrm{~N} \mathrm{HCl}$ or $0.1 \mathrm{~N} \mathrm{NaOH}$.

\subsection{Step-by-step procedure}

First of all, prepare a stock fluoride solution of $20 \mathrm{ppm}$. Then using the stock solution, test solutions $(100 \mathrm{~mL})$ of the desired concentrations ranging from 2 to $12 \mathrm{ppm}$ were obtained by successive dilutions.

Then the weighted amount of adsorbent dose place in a beaker containing fluoride solution and rotate the beaker on a magnetic stirrer for 30-60 min (set rotation at $120-150 \mathrm{rpm}$ ).

After that allow the sample to rest for 10 to $15 \mathrm{~min}$ so that adsorbent could settle down easily and filter the sample through Whatman filter paper of 8 microns.

For analyzing the residual fluoride concentration through UV-VIS Spectrophotometer, take $10 \mathrm{~mL}$ of filtered solution in a test tube and add $1 \mathrm{~mL}$ of SPADNS Zirconyl reagent in the test tube and keep it in rest for 10-15 min for complete mixing.

After that analyze the test solutions for absorbance at standard concentration of fluoride.

Continue to repeat this process by varying adsorbent dose until we get the maximum fluoride removal in the desirable $\mathrm{pH}$ range (6.5-8.5).

Then analyze the adsorbent by varying parameters at the time by keeping the others constant such as contact time, $\mathrm{pH}$, adsorbent dose and initial fluoride concentration.

\subsection{Adsorption isotherms}

Isotherm helps in understanding and analyzing the behavior of contaminants with adsorbent and thus helps in the optimization of surface properties of adsorbent, regenerative capability, and adsorption capacity by knowing the mechanism of adsorption [1, 33, 38]. There are various theories that help in the explanation of adsorption phenomenon viz. Freundlich Isotherm, Langmuir Isotherm, Dubin-Radushkevich Isotherm, and Temkin Isotherm. Among these isotherms, Freundlich and Langmuir Isotherms are most widely used to explain the experimental data of adsorption isotherms [6].

\subsubsection{Langmuir model}

This model has become a mile stone in analyzing the adsorption mechanism and its effectiveness for different adsorbents. The Langmuir relation is given as follows [19, 36] 
$\frac{1}{Q_{e}}=\frac{1}{Q_{m} K_{L} C_{e}}+\frac{1}{Q_{m}}$

where $K_{\mathrm{L}}=$ Langmuir constant $(\mathrm{L} / \mathrm{mg}) ; Q_{\mathrm{m}}=$ Amount of adsorbate when complete monolayer is formed $(\mathrm{mg} / \mathrm{g})$; $C_{e}=$ final concentration at equilibrium $(\mathrm{mg} / \mathrm{L}) ; Q_{e}=$ amount of mass adsorbed per unit mass of adsorbent $(\mathrm{mg} / \mathrm{g})$.

\subsubsection{Freundlich model}

The another model, Freundlich model is also used widely for which equation is as $[19,36]$

$\log Q_{e}=\log K_{\mathrm{f}}+\frac{1}{n} \log C_{\mathrm{e}}$

where $K_{\mathrm{f}}=$ Freundlich capacity factor or called as adsorption capacity $(\mathrm{mg} / \mathrm{g}) ; C_{\mathrm{e}}=$ final concentration at equilibrium (mg/L); $1 / n=$ Freundlich Intensity parameter or called adsorption intensity; $Q_{\mathrm{e}}=$ amount of mass adsorbed per unit mass of adsorbent $(\mathrm{mg} / \mathrm{g})$.

\subsubsection{Kinetic models}

Adsorption Kinetics study helps us in knowing the uptake rate of adsorbate and describing the sorption reaction pathway. It also helps in the estimation of contact time for the adsorption system that requires to design a fixed bed or continuous flow type system. There are various significant factors which govern the adsorption kinetics are surface adsorption, attachment, and movement of fluoride at the interior surface sites, transportation of fluoride from bulk to the outer surface of the adsorbent, precipitation or complexation $[13,38]$.

\subsubsection{Pseudo-first-order}

It is an empirical model which was first described by Lagergren in 1898 for solid liquid adsorption system [24]. Its equation is represented as below [10] $\log \left(q_{e}-q_{t}\right)=\log q_{e}-\frac{k_{1}}{2.303} t$

where, $q_{\mathrm{e}}=$ amount of mass adsorbed per unit mass of adsorbent $(\mathrm{mg} / \mathrm{g}) ; q_{\mathrm{t}}=$ amount of mass adsorbed per unit mass of adsorbent at time $t ; k_{1}=$ rate constant for pseudo first-order kinetics $\left(\mathrm{min}^{-1}\right)$.

\subsubsection{Pseudo-second-order}

This model is based on the sorption equilibrium and assumed that when adsorption follows second-order kinetics, the Chemisorption has taken place between adsorbate and adsorbent $[20,29]$. The pseudo-secondorder equation is as [32]

$\frac{t}{q_{t}}=\frac{1}{k_{2} q_{e}^{2}}+\frac{1}{q_{e}} t$

where, $q_{e}=$ amount of mass adsorbed per unit mass of adsorbent $(\mathrm{mg} / \mathrm{g}) ; q_{t}=$ amount of mass adsorbed per unit mass of adsorbent at time $t ; k_{2}=$ rate constant for pseudo second-order kinetics $\left(\mathrm{g}^{-1} \mathrm{mg}^{-1} \mathrm{~min}^{-1}\right)$.

\section{Results and discussion}

\subsection{Proximate analysis of PCAC}

Results of Proximate analysis for PCAC are mentioned in Table 1. The results indicate that it has a significant percentage, i.e., $21.73 \%$ of fixed carbon which shows its great potential for charcoal preparation [16].

\subsection{Sieve analysis of PCAC}

Calculation regarding sieve analysis is shown in Table 2. Investigated results show that fineness modulus for PCAC is 2.38. Therefore, we can say that the particle size of adsorbent material bears fine-grained particle size within the range of 300 microns to 90 microns as $91 \%$ of the weight was retained in this limit. To obtain sound

Table 1 Calculation for proximate analysis of PCAC

\begin{tabular}{|c|c|c|c|}
\hline Parameter & Wt. (g) & Relation & Percentage $\%$ \\
\hline Sample wt. $\left(W_{1}\right)$ & 11.08 & & \\
\hline Moisture content-Sample dried at $105^{\circ} \mathrm{C}$ for $6 \mathrm{~h}\left(i_{2}\right)$ & 9.426 & $\left(W_{1}-W_{2}\right) \times 100 / W_{1}$ & 14.93 \\
\hline Volatile matter-Sample $W_{2}$ dried at $700-950^{\circ} \mathrm{C}$ for $7 \mathrm{~min}$ in absence of air $\left(W_{3}\right)$ & 2.92 & $\left(W_{2}-W_{3}\right) \times 100 / W_{1}$ & 58.71 \\
\hline $\begin{array}{l}\text { Ash-combustion of the sample takes place at } 550^{\circ} \mathrm{C} \text { for about } 1 \mathrm{~h} \text { or till the ash } \\
\text { formation }\left(W_{4}\right)\end{array}$ & 0.512 & $\mathrm{~W}_{4} \times 100 / \mathrm{W}_{1}$ & 4.62 \\
\hline Fixed carbon & & $\begin{array}{l}\text { 100-(Moisture con- } \\
\text { tent + Volatile mat- } \\
\text { ter + Ash) }\end{array}$ & 21.73 \\
\hline
\end{tabular}


Table 2 Sieve analysis of PCAC

\begin{tabular}{lcll}
\hline $\begin{array}{l}\text { Sieve Size } \\
\text { (micron) }\end{array}$ & $\begin{array}{l}\text { Wt. retained } \\
(\mathrm{mg})\end{array}$ & $\%$ wt. retained & $\begin{array}{l}\text { Cumula- } \\
\text { tive \% wt. } \\
\text { retained }\end{array}$ \\
\hline 600 & 0 & 0 & 0 \\
300 & 71 & 7.1 & 7.1 \\
150 & 251 & 25.1 & 32.2 \\
90 & 664 & 66.4 & 98.6 \\
pan & 14 & 1.4 & 100 \\
\hline
\end{tabular}

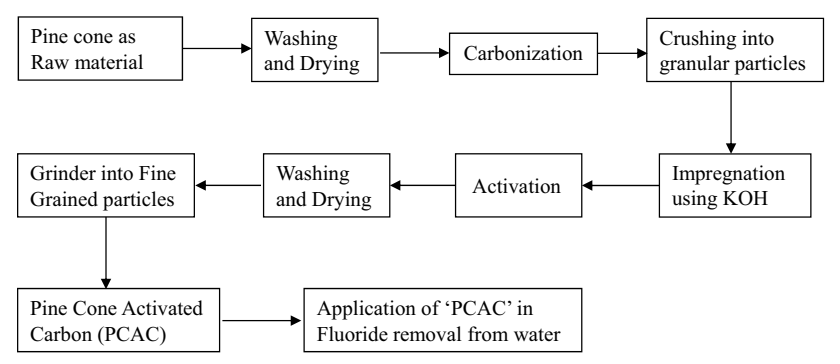

Fig. 1 Flow Chart of PCAC preparation

quality adsorbent material it must possess large surface area which could only be achieved by its fineness [36]. Therefore, prepared adsorbent material using pine cone contains fine-grained particles that have proved efficient in uptake of fluoride (Fig. 1).

\subsection{Scanning electron microscopy (SEM) and energy-dispersive X-ray spectroscopy (EDS) analysis}

SEM helps in analyzing the detailed high-resolution surface images by detecting scattered electrons from the sample surface when a specimen is bombarded by the strong electron beam. Along with SEM, EDS greatly helps in getting information about the involved chemical of a particular sample by analyzing deeply its surface [5]. In the present study, by using SEM and EDS, the PCAC is analyzed before and after fluoride uptake during the adsorption mechanism. It helps in understanding textural morphology and its significance in adsorption. The SEM images and EDS data of PCAC analysis are shown in Fig. 2 and Fig. 3. Figure 2 shows that the PCAC surface bears a significant amount of roughness before fluoride adsorption which was reduced later in fluoride uptake and made the surface smooth and reduced the porosity.

It may be noted in Fig. 3, that the EDS of the PCAC sample indicates elements present in the PCAC sample before and after adsorption. The presence of the potassium (K) element confirmed the impregnation of pine charcoal with $\mathrm{KOH}$ that is shown in 'a' part of Fig. 3. In the elemental percentage given by EDS, the carbon element is maximum in the carbonization step in charcoal formation (refer to Table 3). In 'b' part of Fig. 3, the significant presence of fluoride ion on the adsorbent material surface indicates its uptake by PCAC.

\subsection{Fourier transform infrared spectroscopy (FTIR) analysis of PCAC}

Pine cone charcoal is analyzed in an attempt to find the attached functional group on the adsorbent material. It is effective in analyzing specimens of solid, liquid, and gas. Results indicate that the absorption peak is lying at $3500 \mathrm{~cm}^{-1}$ and this marks the presence of the $\mathrm{O}-\mathrm{H}$ group. It is noted that every type of molecule in organic chemistry marked its presence in some special region called fingerprint with its corresponding bond. For $\mathrm{O}-\mathrm{H}$ functional group absorption band must lie between the wavenumber range (3650-3200) which defines a very strong bond [9] Therefore, it is confirmed that pine cone charcoal has been successfully activated and its validation is shown by FTIR in Fig. 4. The selected values of Wavenumber $\left(\mathrm{cm}^{-1}\right)$ and
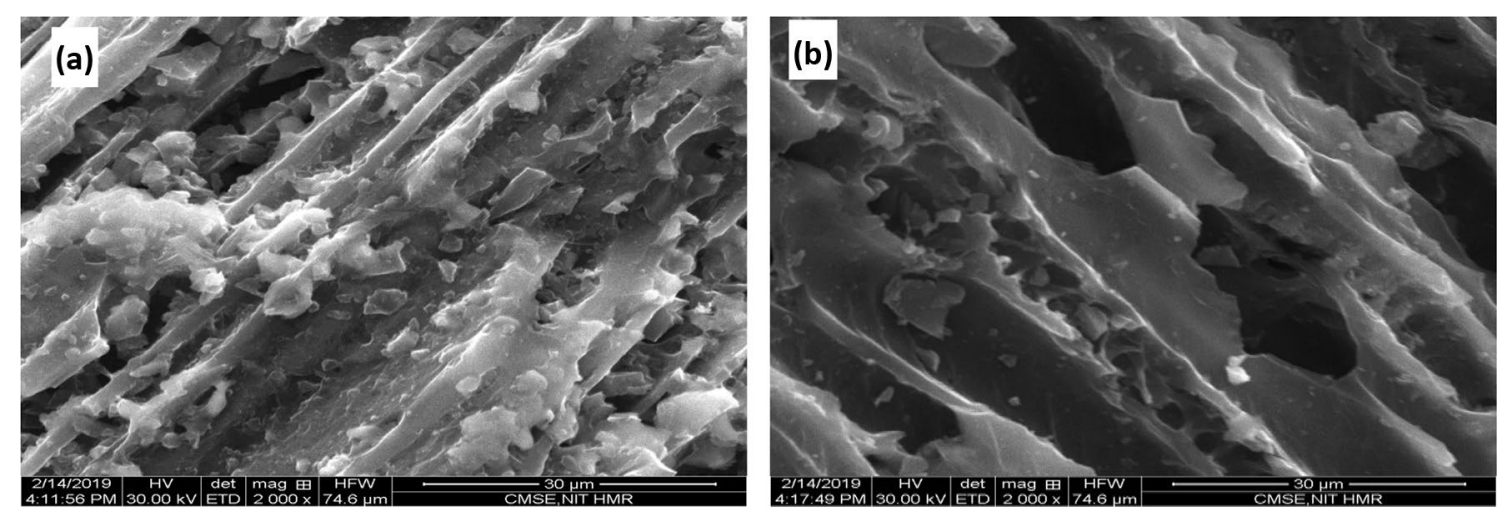

Fig. 2 PCAC surface image at $2000 \mathrm{X}$; a Before adsorption, b After adsorption 


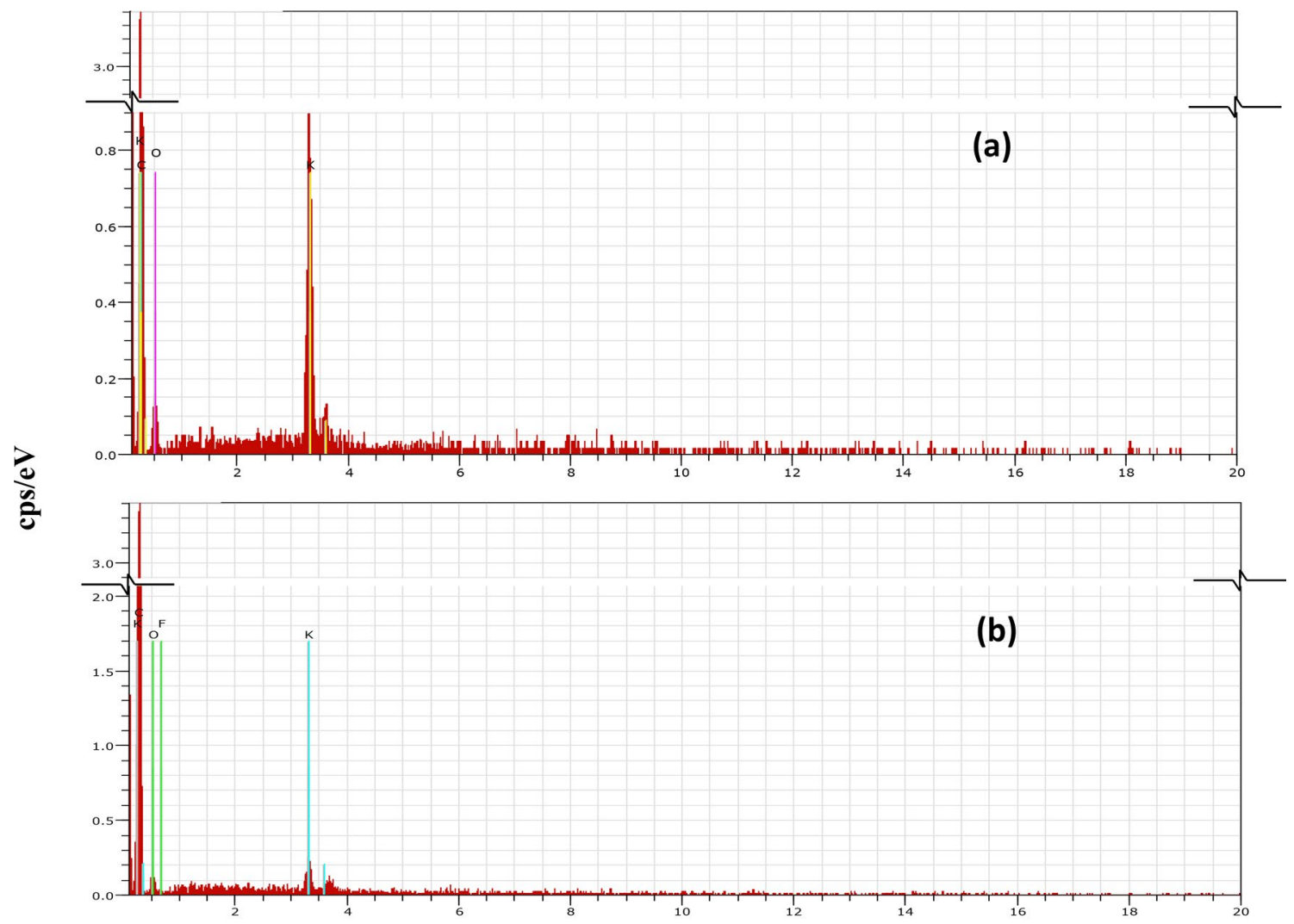

keV

Fig. 3 EDS Graph of PCAC; $\mathbf{a}$ Before adsorption, b After adsorption

Table 3 EDS Chemical composition of PCAC

\begin{tabular}{|c|c|c|c|c|c|c|}
\hline E1 & AN & Series & Unn. (wt \%) & C norm. (wt \%) & C Atom. (wt \%) & C Error (wt \%) \\
\hline \multicolumn{7}{|c|}{ Before adsorption at spectrum: 12,615} \\
\hline C & 6 & $K$-series & 74.32 & 74.32 & 82.65 & 16.7 \\
\hline $\mathrm{O}$ & 8 & K-series & 17.37 & 17.37 & 14.51 & 9.8 \\
\hline \multirow[t]{2}{*}{ K } & 19 & $K$-series & 8.31 & 8.31 & 2.84 & 0.4 \\
\hline & & Total & 100 & 100 & 100 & \\
\hline \multicolumn{7}{|c|}{ After adsorption at spectrum: 12,614} \\
\hline $\mathrm{C}$ & 6 & K-series & 89.04 & 89.04 & 92.04 & 15.1 \\
\hline $\mathrm{O}$ & 8 & $K$-series & 9.37 & 9.37 & 7.27 & 4.9 \\
\hline K & 19 & $K$-series & 1.06 & 1.06 & 0.34 & 0.1 \\
\hline \multirow[t]{2}{*}{$\mathrm{F}$} & 9 & $K$-series & 0.54 & 0.54 & 0.35 & 0.8 \\
\hline & & Total & 100 & 100 & 100 & \\
\hline
\end{tabular}

corresponding \% Transmittance are given in Appendix D which are resulted from FTIR analysis.

\subsection{Effects of parameters on adsorption}

Adsorption depends on significant variables which play a crucial role in fluoride uptake viz. contact time, dose, $\mathrm{pH}$, the strength of fluoride solution [6]. These variables are analyzed to investigate the efficient condition required to develop a strong mechanism for adsorption using an adsorbent material.

\subsubsection{Effect of contact time}

In experimental work test solution of $100 \mathrm{~mL}$ is used with fluoride solution strength of $6 \mathrm{ppm}$. The adsorbent dose 


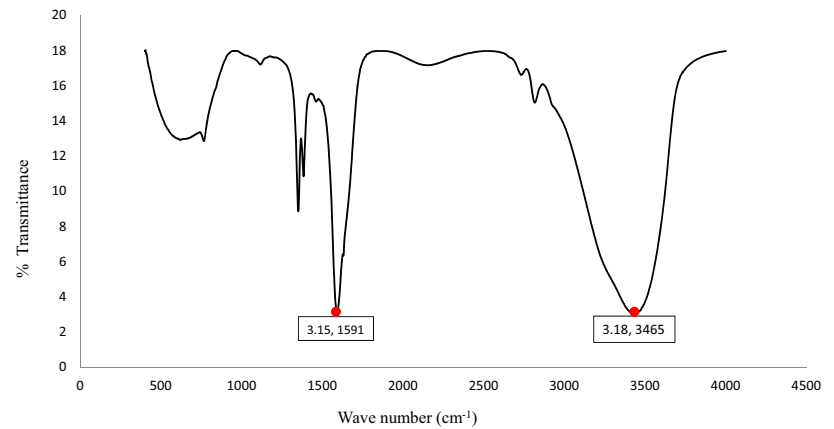

Fig. 4 FTIR of PCAC

in test solutions was taken as 0.5 and 1.0 for PCAC and CAC respectively. The 'a' part of Fig. 5 indicates the effect of increasing contact time and fluoride uptake rate by adsorbent material on increasing contact time. At a certain point, it seems decrement in fluoride uptake rate as time passes and finally, it achieves equilibrium without any enhancement in removal rate. It also interprets that initially fluoride uptake rate is high and after time passes, in medium stage, efficiency begins to reduce because maximum sites are utilized fluoride ion in adhesion or chemical bond formation. In the ending stage, adsorption sites are limited or fully occupied which hindered fluoride uptake rate. This inability of the adsorbent for further adhesion of fluoride ion is depicted by regardless of any time duration. For the PCAC sample, 60 min could be taken as an effective time for efficient fluoride uptake because afterward adsorbent doesn't show any remarkable sign of fluoride uptake regardless of time increased. Similarly, for the CAC sample, 45 min were taken as an effective time.

\subsubsection{Effect of $\mathrm{pH}$}

In the experimental work variation of $\mathrm{pH}$ in the range of 3 to 9 is investigated for fluoride uptake rate. It may be seen from the ' $b$ ' part of Fig. 5 that the fluoride uptake rate is significantly varied in enhancing the $\mathrm{pH}$ level. At lower $\mathrm{pH}$ value higher positive charge is dominating in solution due to the abundant presence of $\mathrm{H}^{+}$ion which gets accumulated around the surface of the adsorbent surface and makes it positively charged. At a lower value of $\mathrm{pH}$ charge of adsorbent is highly positive which helps in fluoride ion adhesion from solution to the adsorbent surface. Therefore, evidence shows maximum fluoride uptake ability of adsorbent gets enhanced at lower $\mathrm{pH}$, and when $\mathrm{pH}$ increases it means there would be less $\mathrm{H}^{+}$ ion which reduces the electropositive charge around the surface of the adsorbent and hence decreases adsorbent uptake ability of fluoride from solution or water.
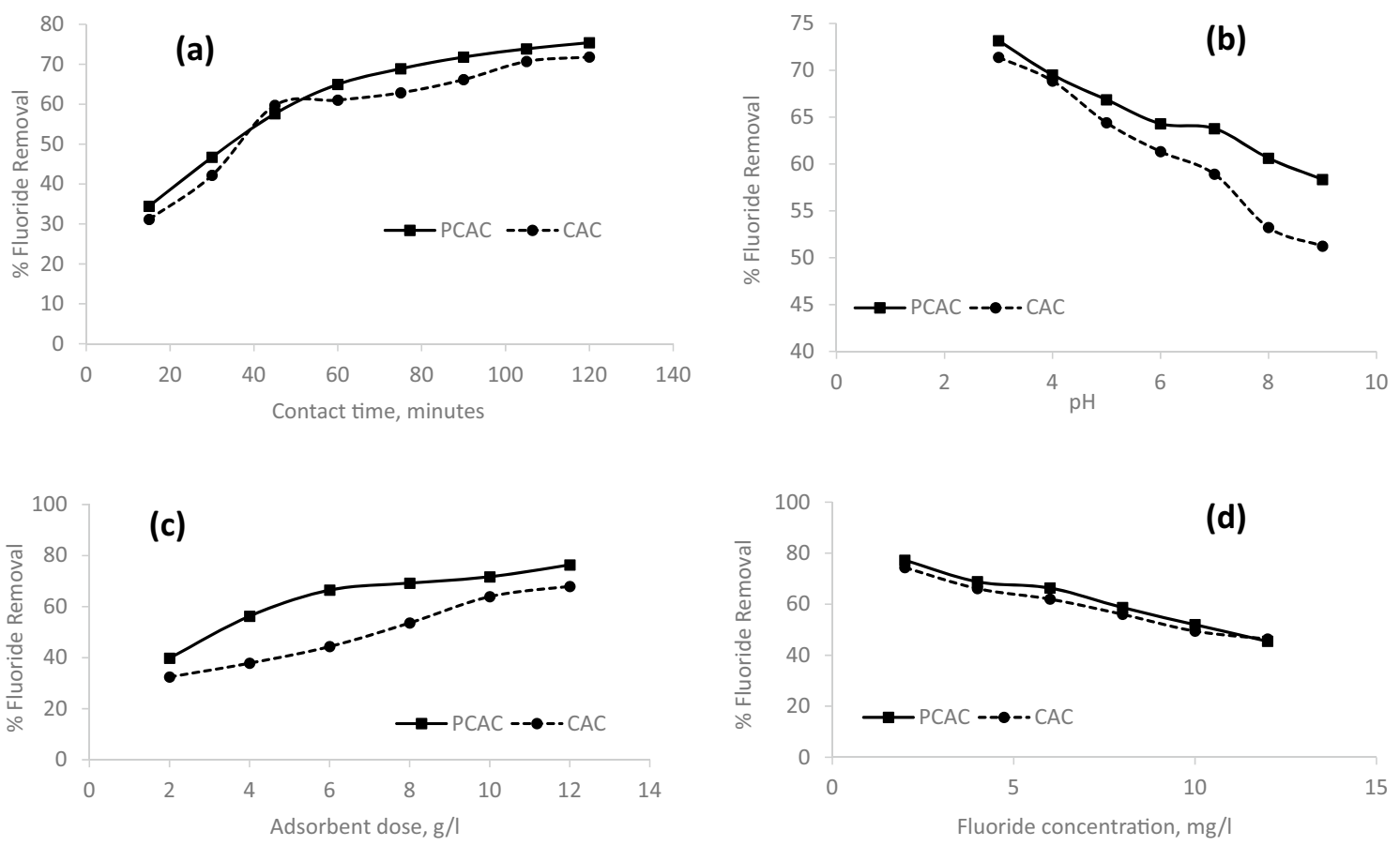

Fig. 5 A comparison for Fluoride removal efficiency between PCAC and CAC for various parameters; $\mathbf{a}$ Contact time, $\mathbf{b} \mathbf{p H}$, $\mathbf{c}$ adsorbent dose, and d Fluoride concentration 


\subsubsection{Effect of adsorbent dose}

The adsorbent dose variation from $0.2 \mathrm{~g}$ to $1.2 \mathrm{~g}$ is investigated in a fluoride solution of $100 \mathrm{~mL}$. Variation in fluoride uptake rate due to variation in adsorbent dose is given in 'c' part of Fig. 5. Experimental studies are varied the adsorbent dose in the range of $\mathrm{pH} 6.8-7.0$ and contact time $45 \mathrm{~min}$ for CAC and $60 \mathrm{~min}$ for PCAC. From Fig. 5 , it is concluded that with increment in the dose of adsorbent material fluoride uptake rate increases up to a certain extent due to maximum vacant sites and pores availability for adsorption. But when doses increase from 8-12 $\mathrm{g} / \mathrm{L}$ there was not any remarkable change in fluoride removal ability because of maximum adsorbent dose sites that have overlapped which results in the reduction of net surface area [11].

\subsubsection{Effect of initial fluoride concentration}

Variation in fluoride uptake rate with varying fluoride concentration is plotted in 'd' part of Fig. 5. The effect of initial solution concentrations was investigated in the range of 2-12 ppm at fixed adsorbent dose, $\mathrm{pH}$, and time previously determined. Initially, the fluoride uptake ability is maximum because of the availability of maximum unoccupied sites on the surface of the adsorbent. As the concentration increases, sites get occupied and on a further increment of fluoride solution strength, the adsorption became ineffective which is highlighted from constant graph line because already all adsorbent sites have been occupied and material gets saturated.

\subsection{Adsorption isotherm}

Adsorption isotherm modeling is done for PCAC and CAC at fluoride solution strength of $2 \mathrm{mg} / \mathrm{L}$ to $12 \mathrm{mg} / \mathrm{L}$. In the present analysis of the Isotherm models, trend analysis represents the best fit relation with each selected Isotherm model by checking the linear relationship and its correlation using the regression value of $R^{2}$. A comparison between Freundlich and Langmuir isotherm models for pine cone based activated charcoal and market based activated charcoal indicate the suitability of Langmuir isotherm for fluoride adsorption. This shows that the mechanism of adsorption depends on monolayer formation by adsorbate on the material surface. Figure 6 represents the Isotherms models for PCAC and CAC.

Investigation of Adsorption isotherm indicates the suitability of PCAC over CAC (refer to Table 4). On analyzing the isotherm model, Langmuir isotherm gives the best correlation over Freundlich isotherm by $R^{2}$ value of 0.992 . This indicates the acceptability of pine based charcoal over market-based charcoal for fluoride removal. In Langmuir isotherm, $R_{L}$ denotes the adsorption nature and its acceptability. By investigating the Isotherm in case of Langmuir, $R_{L}$ value for fluoride solution strength of $2-12 \mathrm{mg} / \mathrm{L}$ is found in the range of 0.435 to 0.114 for PCAC and 0.476 to 0.131 for CAC. Dada et al. [10] and Dehghani et al. [13] (a)

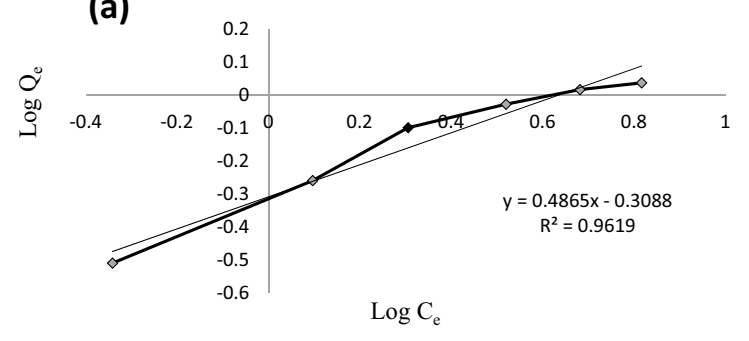

(c)

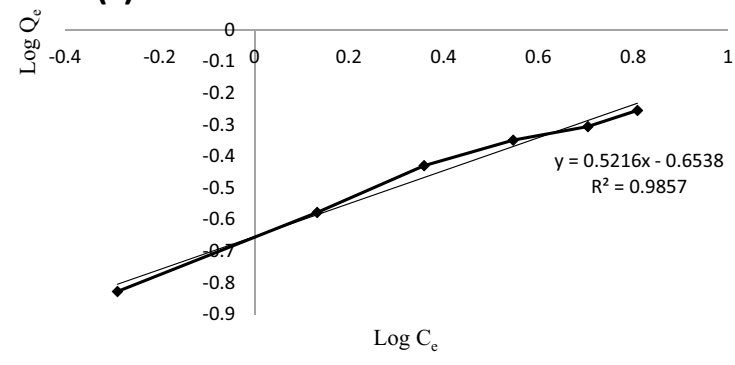

(b)

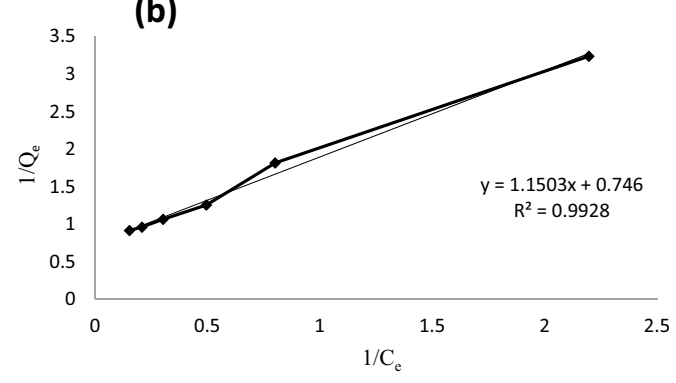

(d)

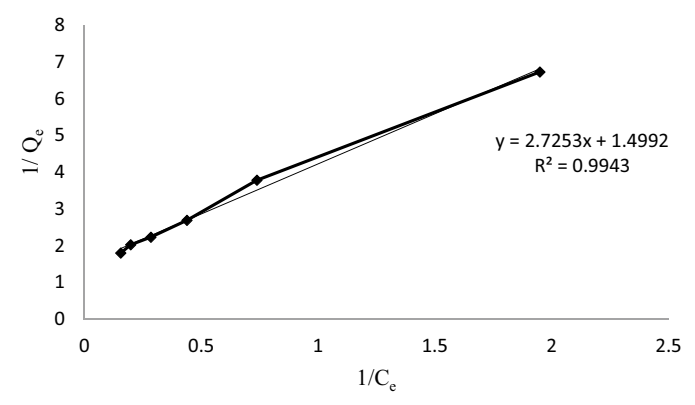

Fig. 6 Adsorption Isotherm plots; a Freundlich isotherm for PCAC, b Langmuir isotherm for PCAC, c Freundlich isotherm for CAC, and d Langmuir isotherm for CAC Plot of Langmuir isotherm for fluoride adsorption (CAC) 
Table 4 Adsorption isotherm results for PCAC and CAC

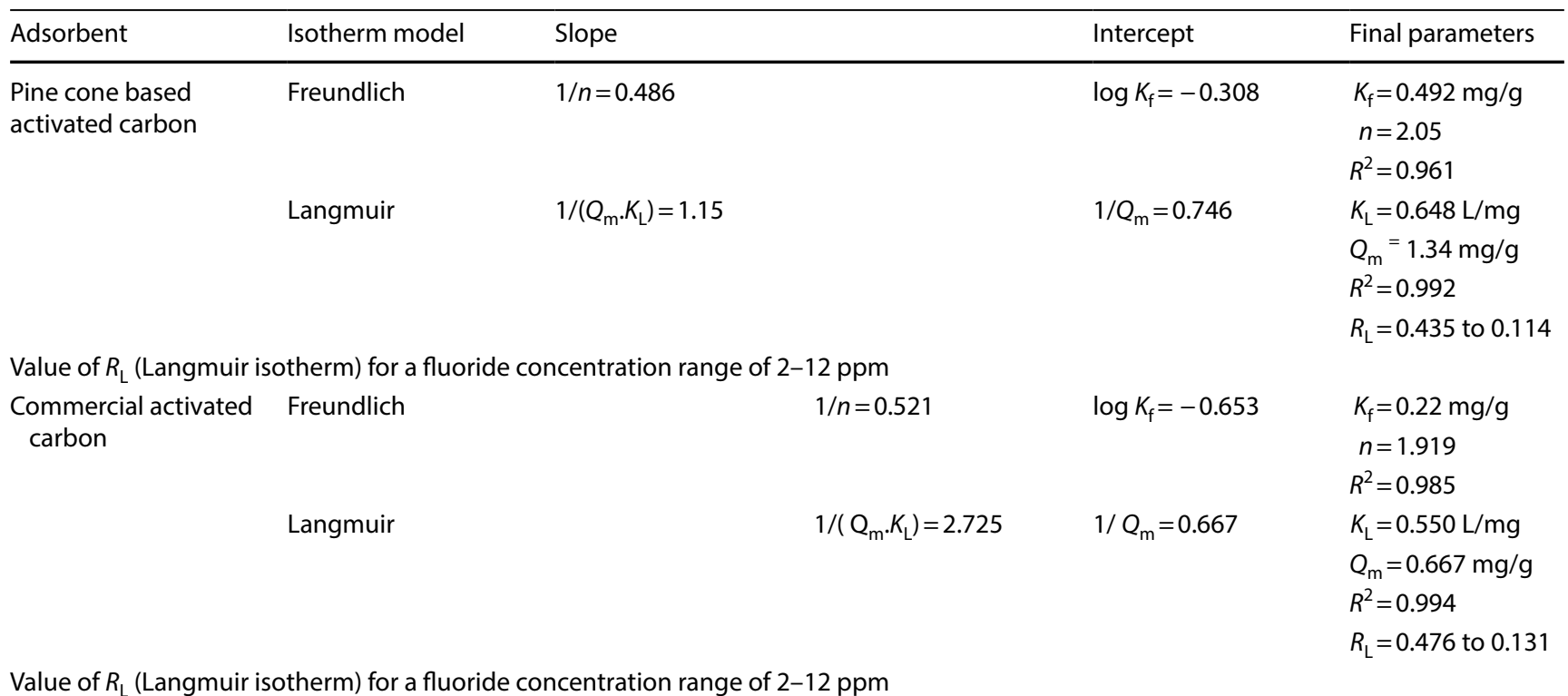

show that $R_{L}$ in both cases lies between 0 and 1 which indicates that fluoride uptake is favorable and confirms its acceptability on activated charcoal in both cases.

\subsection{Adsorption kinetics model}

Adsorption kinetic modeling is done for PCAC and CAC at fluoride solution strength of $6 \mathrm{mg} / \mathrm{L}$ with varying contact time. An analysis of the kinetic model, a comparison between Pseudo-first-order and Pseudo second-order, both kinetic model for PCAC and CAC indicate the suitability of second-order kinetics for fluoride adsorption. This shows that the mechanism of adsorption depends on chemical bonding between adsorbate and material surface. Figure 7 represents the kinetic models for PCAC and CAC.

Also, the suitability of PCAC over CAC may be referred from Table 5. On analyzing kinetics models, second-order kinetics gives the best correlation over first order by the $R^{2}$ value of 0.998 . This indicates the acceptability of PCAC over CAC for fluoride removal and shows its ability to uptake rate. The second-order kinetic model indicates the significant and crucial role of chemisorption in the mechanism of adsorption for fluoride removal by PCAC. Many previous studies on fluoride removal reported the adsorption kinetics as second-order kinetics [6] and the exact explanation of the second-order kinetics is based on the $R^{2}[11,18,28]$.

The rate constant for PCAC is greater than CAC and have $k_{1}$ value $0.0345 \mathrm{~min}^{-1}$. A higher value of rate constant determines the ability of adsorbent which indicates a higher uptake rate. Fluoride uptake rate for PCAC is
$1.12 \mathrm{mg} / \mathrm{g}$ which is more than double as compared to the CAC uptake rate of $0.531 \mathrm{mg} / \mathrm{g}$. Investigation through kinetic studies shows the significant ability of PCAC over $C A C$. Hence PCAC is a better alternative as compared to $C A C$ for fluoride removal from water.

\section{Conclusion}

In the present study, an adsorbent is prepared using pine cones as raw material that has good availability in an Indian state Himachal Pradesh, lying foothills of the Himalayan range. Proximate analysis results indicate the significance and suitability of pine cones as a rich source of carbon; it contains about $21.3 \%$ fixed carbon which is a crucial factor in adsorbent preparation. Adsorption studies conducted using isotherm and kinetic models proved that its adsorption capacity is quite reliable as compared to market-based activated carbon. The maximum adsorption capacity of PCAC is investigated by Langmuir isotherm and shows a quite impressive adsorption ability of $1.34 \mathrm{mg} / \mathrm{g}$ as compared to CAC with adsorption ability of $0.667 \mathrm{mg} / \mathrm{g}$ in $\mathrm{pH}$ range 6.5-7.5. Adsorption kinetics indicate the suitability of pseudo-second-order by providing the best-fit correlation for adsorption. According to the kinetic model, PCAC has shown maximum adsorption ability for fluoride which is $1.12 \mathrm{mg} / \mathrm{g}$ as compared to CAC having an uptake rate of $0.531 \mathrm{mg} / \mathrm{g}$ of fluoride. In addition, the results conclude the ability of PCAC for the good potential for fluoride removal from drinking water. It is also suggested that the adsorption capacity of PCAC can be enhanced further by developing the higher 
(a)

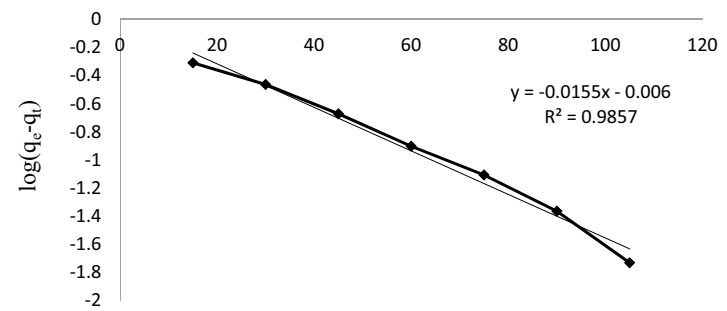

time (min)

(c)

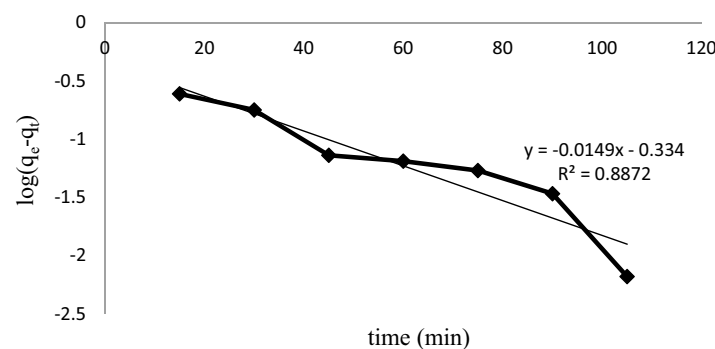

(b)

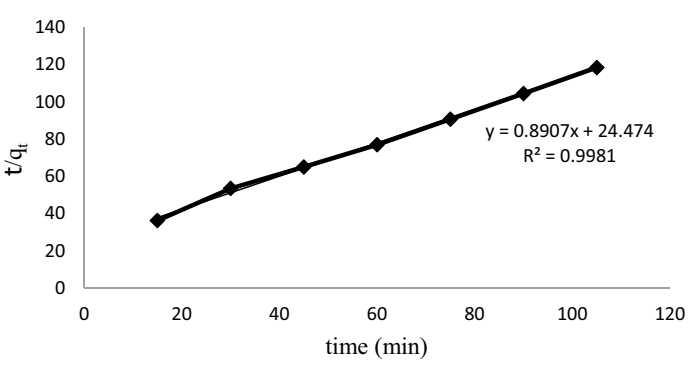

(d)

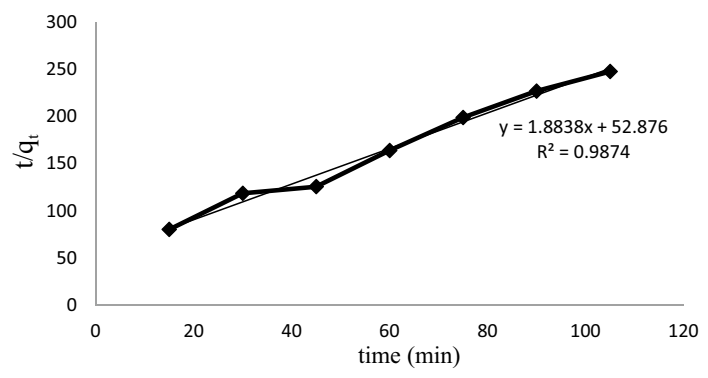

Fig. 7 Adsorption kinetics model plots; a Pseudo-first-order kinetics for PCAC, b Pseudo-second-order kinetics for PCAC, c Pseudo-firstorder kinetics for CAC, and $\mathbf{d}$ Pseudo-second-order kinetics for CAC

Table 5 Adsorption kinetic results for PCAC and CAC

\begin{tabular}{|c|c|c|c|c|}
\hline Adsorbent & Kinetic model & Slope & Intercept & Final parameters \\
\hline \multirow[t]{2}{*}{ Pine cone-based activated carbon } & Pseudo-first-order & $-k_{1} / 2.303=-0.015$ & $\log q_{\mathrm{e}}=-0.006$ & $\begin{array}{l}k_{1}=0.0345 \mathrm{~min}^{-1} \\
q_{\mathrm{e}}=0.986 \mathrm{mg} / \mathrm{g} \\
R^{2}=0.985\end{array}$ \\
\hline & Pseudo-second-order & $1 / q_{\mathrm{e}}=0.890$ & $1 /\left(k_{2} q_{\mathrm{e}}^{2}\right)=24.47$ & $\begin{array}{l}k_{2}=0.180 \mathrm{~g} / \mathrm{mg} \min \\
q_{\mathrm{e}}=1.12 \mathrm{mg} / \mathrm{g} R^{2}=0.998\end{array}$ \\
\hline \multirow[t]{2}{*}{ Commercial activated carbon } & Pseudo-first-order & $-k_{1} / 2.303=-0.014$ & $\log q_{\mathrm{e}}=-0.334$ & $\begin{array}{l}k_{1}=0.0322 \mathrm{~min}^{-1} \\
q_{\mathrm{e}}=0.463 \mathrm{mg} / \mathrm{g} \\
R^{2}=0.887\end{array}$ \\
\hline & Pseudo-second-order & $1 / q_{\mathrm{e}}=1.883$ & $1 /\left(k_{2} q_{\mathrm{e}}^{2)}=52.87\right.$ & $\begin{array}{l}k_{2}=0.259 \mathrm{~g} / \mathrm{mg} \min \\
q_{\mathrm{e}}=0.531 \mathrm{mg} / \mathrm{g} \\
R^{2}=0.987\end{array}$ \\
\hline
\end{tabular}

surface area as compared to present techniques which may increase the uptake rate if impregnated with some other chemicals or its combination. Certainly, this study will help for better studies on a pine cone in the future by discovering the hidden potential and enhancing the capability of a pine cone as great adsorbent.

Author contributions R.S.T. and S.S.K. conceived and designed the analysis. R.S.T. performed the analysis; S.S.K. supervised the research; A.M. and R.S.T. reviewed the analysis. A.M. wrote and edited the manuscript.

\section{Compliance with ethical standards}

Conflicts of interest There authors declare that they have no conflicts of interest.

\section{References}

1. Alagumuthu G, Rajan M (2010) Equilibrium and kinetics of adsorption of fluoride onto zirconium impregnated cashew nut shell carbon. Chem Eng J 158:451-457. https://doi. org/10.1016/j.cej.2010.01.017

\section{SN Applied Sciences}


2. Ali I, Asim M, Khan TA (2012) Low cost adsorbents for the removal of organic pollutants from wastewater. J Environ Manage 113:170-183

3. Araga R, Soni S, Sharma CS (2017) Fluoride adsorption from aqueous solution using activated carbon obtained from $\mathrm{KOH}-$ treated jamun (Syzygium cumini) seed. J Environ Chem Eng 5:5608-5616. https://doi.org/10.1016/j.jece.2017.10.023

4. Ayoob S, Gupta AK (2006) Fluoride in drinking water: a review on the status and stress effects. Crit Rev Environ Sci Technol 36:433-487. https://doi.org/10.1080/10643380600678112

5. Baig U, Uddin MK, Gondal MA (2020) Removal of hazardous azo dye from water using synthetic nano adsorbent: facile synthesis, characterization, adsorption, regeneration and design of experiments. Colloids Surf Physicochem Eng Asp 584:124031. https:// doi.org/10.1016/j.colsurfa.2019.124031

6. Bhatnagar A, Kumar E, Sillanpää M (2011) Fluoride removal from water by adsorption-a review. Spec Sect Symp Post-Combust Carbon Dioxide Capture 171:811-840. https://doi.org/10.1016/j. cej.2011.05.028

7. Bhatnagar A, Vilar VJP, Botelho CMS, Boaventura RAR (2011) A review of the use of red mud as adsorbent for the removal of toxic pollutants from water and wastewater. Environ Technol 32:231-249. https://doi.org/10.1080/09593330.2011.560615

8. Cases A, Coll E (2005) Dyslipidemia and the progression of renal disease in chronic renal failure patients. Proc Second Int Conf New Insights Progress Chronic Kidney Dis 68:S87-S93. https:// doi.org/10.1111/j.1523-1755.2005.09916.x

9. Coates J (2006) Interpretation of infrared spectra, a practical approach. In: Meyers RA (ed) Encyclopedia of analytical chemistry. American Cancer Society, Atlanta

10. Dada AO, Olalekan AP, Olatunya AM, Dada O (2012) Langmuir Freundlich, Temkin and Dubinin-Radushkevich isotherms studies of equilibrium sorption of $\mathrm{Zn} 2+$ unto phosphoric acid modified rice husk. IOSR J Appl Chem 3:38-45

11. Daifullah AAM, Yakout SM, Elreefy SA (2007) Adsorption of fluoride in aqueous solutions using $\mathrm{KMnO} 4$-modified activated carbon derived from steam pyrolysis of rice straw. J Hazard Mater 147:633-643. https://doi.org/10.1016/j.jhazmat.2007.01.062

12. De Gisi S, Lofrano G, Grassi M, Notarnicola M (2016) Characteristics and adsorption capacities of low-cost sorbents for wastewater treatment: a review. Sustain Mater Technol 9:10-40. https ://doi.org/10.1016/j.susmat.2016.06.002

13. Dehghani $M H$, Farhang $M$, Alimohammadi $M$ et al (2018) Adsorptive removal of fluoride from water by activated carbon derived from $\mathrm{CaCl}$-modified Crocus sativus leaves: equilibrium adsorption isotherms, optimization, and influence of anions. Chem Eng Commun 205:955-965. https://doi.org/10.1080/00986 445.2018.1423969

14. Delgadillo-Velasco L, Hernández-Montoya V, Cervantes FJ et al (2017) Bone char with antibacterial properties for fluoride removal: preparation, characterization and water treatment. J Environ Manage 201:277-285. https://doi.org/10.1016/j.jenvm an.2017.06.038

15. Ghosh A, Mukherjee K, Ghosh SK, Saha B (2013) Sources and toxicity of fluoride in the environment. Res Chem Intermed 39:2881-2915. https://doi.org/10.1007/s11164-012-0841-1

16. Gil RR, Ruiz B, Lozano MS, Fuente E (2014) Influence of the pyrolysis step and the tanning process on $\mathrm{KOH}$-activated carbons from biocollagenic wastes. Prospects as adsorbent for CO2 capture. J Anal Appl Pyrolysis 110:194-204. https://doi. org/10.1016/j.jaap.2014.09.001

17. Gupta IP, Das TK, Susheela AK et al (1992) Fluoride as a possible aetiological factor in non-ulcer dyspepsia. J Gastroenterol Hepatol 7:355-359. https://doi.org/10.1111/j.1440-1746.1992.tb009 $96 . x$
18. Gupta VK, Ali I, Saini VK (2007) Defluoridation of wastewaters using waste carbon slurry. Water Res 41:3307-3316

19. Helfferich FG (1995) Ion exchange. Courier Corporation, Chelmsford

20. Ho Y, McKay G (1998) A comparison of chemisorption kinetic models applied to pollutant removal on various sorbents. Trans IChemE 76:332-340

21. IS 3025 (Part 60) (2008) Indian Standard: methods of sampling and test (physical and chemical) for water and wastewater: PART 60 Fluoride

22. Jagtap S, Yenkie MK, Labhsetwar N, Rayalu S (2012) Fluoride in drinking water and defluoridation of water. Chem Rev 112:2454-2466. https://doi.org/10.1021/cr2002855

23. Jha SK, Mishra VK, Sharma DK, Damodaran T (2011) Fluoride in the environment and its metabolism in humans. In: Whitacre DM (ed) Reviews of environmental contamination and toxicology, vol 211. Springer, New York, pp 121-142

24. Lagergren SK (1898) About the theory of so-called adsorption of soluble substances. Sven Vetenskapsakad Handingarl 24:1-39

25. Li Y, Li X, Wei S (1994) Effect of excessive fluoride intake on mental work capacity of children and a preliminary study of its mechanism. J West China Univ Med Sci 25:188-191

26. Meenakshi MRC (2006) Fluoride in drinking water and its removal. J Hazard Mater 137:456-463. https://doi.org/10.1016/j. jhazmat.2006.02.024

27. Mohapatra M, Anand S, Mishra BK et al (2009) Review of fluoride removal from drinking water. J Environ Manage 91:67-77. https ://doi.org/10.1016/j.jenvman.2009.08.015

28. Mohapatra M, Rout K, Gupta SK et al (2010) Facile synthesis of additive-assisted nano goethite powder and its application for fluoride remediation. J Nanoparticle Res 12:681-686. https:// doi.org/10.1007/s11051-009-9779-7

29. Momčilović M, Purenović M, Bojić A et al (2011) Removal of lead(II) ions from aqueous solutions by adsorption onto pine cone activated carbon. Desalination 276:53-59. https://doi. org/10.1016/j.desal.2011.03.013

30. Mullenix PJ, Denbesten PK, Schunior A, Kernan WJ (1995) Neurotoxicity of sodium fluoride in rats. Neurotoxicol Teratol 17:169177. https://doi.org/10.1016/0892-0362(94)00070-T

31. NRC (2006) Fluoride in drinking water: a scientific review of EPA's standards Committee on fluoride in drinking water. National Research Council, Washington, D.C.

32. Plazinski W, Dziuba J, Rudzinski W (2013) Modeling of sorption kinetics: the pseudo-second order equation and the sorbate intraparticle diffusivity. Adsorption 19:1055-1064. https://doi. org/10.1007/s10450-013-9529-0

33. Ravulapalli S, Kunta R (2017) Defluoridation studies using active carbon derived from the barks of Ficus racemosa plant. J Fluor Chem 193:58-66. https://doi.org/10.1016/j.jfluc hem.2016.11.013

34. Singh PP, Barjatiya MK, Dhing S et al (2001) Evidence suggesting that high intake of fluoride provokes nephrolithiasis in tribal populations. Urol Res 29:238-244. https://doi.org/10.1007/ s002400100192

35. Sivasankar V, Rajkumar S, Murugesh S, Darchen A (2012) Influence of shaking or stirring dynamic methods in the defluoridation behavior of activated tamarind fruit shell carbon. Chem Eng J 197:162-172. https://doi.org/10.1016/j.cej.2012.05.023

36. Slejko FL (1985) Adsorption technology: a step-by-step approach to process evaluation and application. M. Dekker, New York

37. Susheela AK, Toteja G (2018) Prevention \& control of fluorosis \& linked disorders: developments in the twenty-first Centuryreaching out to patients in the community \& hospital settings for recovery. Indian J Med Res 148:539 
38. Talat M (2018) Effective removal of fluoride from water by coconut husk activated carbon in fixed bed column: experimental and breakthrough curves analysis. Groundw Sustain Dev 7:4855. https://doi.org/10.1016/j.gsd.2018.03.001

39. Wang S, Peng Y (2010) Natural zeolites as effective adsorbents in water and wastewater treatment. Chem Eng J 156:11-24

40. Xiang Q, Liang Y, Chen L et al (2003) Effect of fluoride in drinking water on children's intelligence. Fluoride 36:84-94
Publisher's Note Springer Nature remains neutral with regard to jurisdictional claims in published maps and institutional affiliations.

\section{SN Applied Sciences}

